\title{
Design of a System for Supply of Plants Based On Tugger-Type Train with Modifications in Wagons
}

\author{
Luis Ramirez, Luis Felipe Rincon Betancur, Lizeth Maria Salgado Castro \\ FCIMEC, Colombia
}

\begin{abstract}
This research shows the design process and the selection of a new transportation system within a food production company based on a tugger cargo truck for raw materials supply, guaranteeing the production plants. This publication presents the differents criteria making the selection of this means of transport among several alternatives that were taken into account as possible options, the calculation of the required capacity of said means of transport, the design of the route that should carry out taking into account the flow of material in the company and how was the design of the system considering all restrictions; that it could rise to different heights, that it incorporates a protection system against inclement weather, being able to open and automatically close its gates to be able to unload the product simply and also design it so that it can move without problem in terrain with different slopes.
\end{abstract}

Keywords: transport, logistics, supply, tugger, equipment selection 